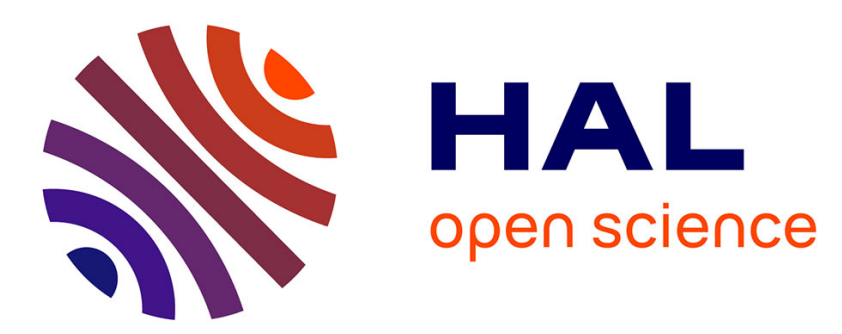

\title{
Dynamics of pollutant discharge in combined sewer systems during rain events: chance or determinism?
}

\author{
A. Hannouche, G. Chebbo, C. Joannis
}

\section{To cite this version:}

A. Hannouche, G. Chebbo, C. Joannis. Dynamics of pollutant discharge in combined sewer systems during rain events: chance or determinism?. Water Science and Technology, 2014, 69 (8), pp.1751-8. 10.2166/wst.2014.088 . hal-01064407

\section{HAL Id: hal-01064407 https://hal-enpc.archives-ouvertes.fr/hal-01064407}

Submitted on 16 Sep 2014

HAL is a multi-disciplinary open access archive for the deposit and dissemination of scientific research documents, whether they are published or not. The documents may come from teaching and research institutions in France or abroad, or from public or private research centers.
L'archive ouverte pluridisciplinaire HAL, est destinée au dépôt et à la diffusion de documents scientifiques de niveau recherche, publiés ou non, émanant des établissements d'enseignement et de recherche français ou étrangers, des laboratoires publics ou privés. 


\title{
Dynamics of pollutant discharge in combined sewer systems during rain events: chance or determinism?
}

\author{
Hannouche, A. ${ }^{*}$; Chebbo, G. ${ }^{*, * *} ;$ Joannis, C. ${ }^{* * *}$ \\ Université Paris-Est, LEESU (UMR-MA-102), UPEC, UPEMLV, ENPC, Agro \\ ParisTech, 6 et 8 avenue Blaise Pascal - Cité Descartes, 77455 Champs-sur-Marne \\ Cedex 2, France (corresponding author, +33164153950; ali.hannouche@leesu.enpc.fr) \\ ** Faculty of Engineering III, Lebanese University, Rafic Hariri university campus- \\ Lebanon (gksc@terra.net.lb); \\ **** IFSTTAR - Centre de Nantes- Département géotechnique eau et risques - route de \\ Bouaye CS4 - 44344 Bouguenais cedex (claude.joannis@ifsttar.fr).
}

\begin{abstract}
A large database of continuous flow and turbidity measurements cumulating data on hundreds of rain events and dry weather days from two sites in Paris (called "Quais" and "Clichy") and one in Lyon (called "Ecully") is presented. This database is used to characterize and compare the behaviour of the three sites at the inter-events scale. The analysis is probed through three various variables: total volumes and TSS masses and concentrations during both wet and dry weather periods in addition to the contributions of diverse-origin sources to event flow volume and TSS load values.

The results obtained confirm the previous findings regarding the spatial consistency of TSS fluxes and concentrations between both sites in Paris having similar land uses. Moreover, masses and concentrations are proven to be correlated between Parisian sites in a way that implies the possibility of some deterministic processes being reproducible from one catchment to another for a particular rain event.

The results also demonstrate the importance of the contribution of wastewater and sewer deposits to the total events' loads and show that such contributions are not specific to Paris sewer networks.
\end{abstract}

Keywords: Combined sewer, spatial coherence, variability, sources, mass, concentration, turbidity, TSS.

\section{INTRODUCTION}

Many studies have been conducted over the last forty years to examine pollutant fluxes in urban wet-weather discharges (UWWD) (Suarez and Puertas, 2005; Schilperoort, 2011; Gasperi et al., 2012), to determine their temporal and spatial variations (Lee \& Bang, 2000; Kafi et al., 2008) and to describe their entry into combined sewer systems (Gromaire-Mertz et $a l ., 1999)$. These studies globally assess the importance of pollutant fluxes in UWWD and provide information on the characteristics and origins of pollutants (Gasperi et al., 2010). Current studies also describe, though rather approximately, pollutants' generation and transport processes (Ashley et al., 1999). The results show that both pollutant concentrations and fluxes vary greatly not only during event but also between events.

Yet, Kafi et al. (2008) have observed some similar behaviours, as regards fluxes and concentrations of TSS (also concentrations of other parameters: COD, $\mathrm{BOD}_{5}$, metals ...), among six catchments, covering land areas varying from 41 to $2581 \mathrm{ha}$ and containing quite similar land uses.

However, these previous results, specifically the spatial homogeneity, were obtained using a small set of rainfall event data recorded using conventional sampling methods (only a limited 
number of samples per event and only some events can be sampled). More recently, continuous turbidity measurements have allowed the recording of a time series in either dry or wet weather conditions. These measurements are representative of the present TSS (principal carriers of contaminants) when transformed into TSS concentration using an average TSSTurbidity relationship on different time-scales (Lacour et al., 2009; Hannouche et al., 2011; Metadier and Bertrand-Krajewski, 2012).

The French observatories in urban hydrology SOERE URBIS (A long-term Observation System for research and Experimentation on urban environment) are composed of OPURParis (Observatory of Urban Pollutants in Île-de-France/Paris region), OTHU-Lyon (Field Observatory for Urban Water Management in Lyon-France) and ONEVU-Nantes (Observatory of urban environments of Nantes-France). They provided some statistically representative databases for water flow and turbidity measurements at the outlet of two catchments in Paris (Quais and Clichy) and one in Lyon (Ecully). The aim of this paper is to assess the variability of TSS fluxes and concentrations observed at the outlet of these catchments during both wet and dry weather periods using the SOERE "URBIS" database records. Results obtained on sites with similar or different characteristics are then compared.

\section{EXPERIMENTAL DATA}

\section{Description of the sites}

Two experimental catchments in Paris-France, called "Quais" and "Clichy", are monitored within the framework of the "OPUR" research program. The OPUR program addresses the generation, the transport and the treatment of pollutant loads due to urban water discharges. Both catchments are located in a downtown densely urbanized and are served by a combined sewer system. The main characteristics of both catchments are displayed in Table 1. The Quais catchment is totally embedded in the Clichy catchment, which implies that the variables observed at the outlet of both catchments are partly redundant. To neutralize this redundancy, volume, mass and concentration are assessed for the complementary fraction of the "Quais" catchment inside the "Clichy" catchment (denoted "Outside Quais"). Data treatment processing, then, consists of subtracting the masses and volumes observed in "Clichy" and "Quais" for the same rainfall event.

The Paris sewer system is known for its high deposit level. Deposit contribution to TSS load during rain events is assessed at more than $40 \%$ (Gasperi et al., 2010).

Table 1: Main characteristics of the studied sites.

\begin{tabular}{|c|c|c|c|c|}
\hline Catchments & Quais & Clichy & Outside Quais & Ecully \\
\hline Land uses & $\begin{array}{l}\text { Dense } \\
\text { urban }\end{array}$ & $\begin{array}{l}\text { Dense } \\
\text { urban }\end{array}$ & Dense urban & residential \\
\hline Surface area (ha) & 402 & 942 & 540 & 245 \\
\hline Runoff coefficient (-) & 0.64 & 0.68 & 0.71 & 0.15 \\
\hline Active surface $^{(*)}$ (act.ha) (ha) & 257 & 641 & 383 & 37 \\
\hline Median slope $(\%)$ & 0.14 & 0.10 & 0.11 & 2.7 \\
\hline Equivalent inhabitant $\mathrm{BOD}_{5}\left(\mathrm{EI}^{(* *)} /\right.$ act.ha $)$ & 600 & 680 & 730 & 220 \\
\hline Average dry weather daily flow (1/EI/day) & 450 & 400 & 375 & 380 \\
\hline
\end{tabular}

We also use the data available at the "INSA of Lyon" for the catchment area of "Ecully" as part of the "OTHU" research program (Field Observatory for Urban Hydrology) (Metadier and Bertrand-Krajewski, 2012). In comparison with both Paris sites, "Ecully"'s characteristics are quite different: low population density, residential area with steep slopes, and no street 
cleaning. Moreover, there is no place of coarse deposits accumulation observed in the Ecully combined sewer system (Metadier and Bertrand-Krajewski, 2012).

\section{Equipments and available data set}

Both Paris sites are equipped with two redundant turbidity sensors (Ponsel brand with: attenuation at $880 \mathrm{~nm}$, calibration using formazin and a range $=0-2000 \mathrm{FAU}$ ), a conductivity sensor (Ponsel brand) and a flow-rate sensor (CR2M SAB600 model, ultrasonic time-of-flight flowmeters). The turbidity sensors are automatically cleaned every 15 minutes and manually cleaned and maintained every second week. The zero-drift and endpoint calibration is also verified. For each site, the final turbidity signal was derived from both available signals once their consistency had been verified. Turbidity, conductivity and flow-rate are recorded every 1 minute on both sites during all the rainfall events in 2006. Data have been processed and validated by (Lacour et al., 2009).

Storm events are identified using flow rate and conductivity data. The beginning of the event is given by the rise of the flow rate and a sharp drop in the conductivity signal whereas the end of the event is given by the return to the dry weather conductivity. During the year 2006, 74 rainfall events have been identified for "Quais" and 88 for "Clichy", among which 70 events occurred simultaneously on both catchments ("Quais" and "Clichy", see Table 2). Furthermore, we identified 221 complete dry weather days for 'Quais' and 215 for "Clichy", including 209 days common to both sites.

Table 2: Main rainfall characteristics of the identified rain events on Quais and Clichy.

\begin{tabular}{cccccc}
\hline & $\begin{array}{c}\text { Rain depth } \\
(\mathrm{mm})\end{array}$ & $\begin{array}{c}\text { Mean intensity } \\
\left(\mathrm{mm} \cdot \mathrm{h}^{-1}\right)\end{array}$ & $\begin{array}{c}\text { Max 5-min Rainfall } \\
\text { intensity }\left(\mathrm{mm}^{-1}\right)\end{array}$ & $\begin{array}{c}\text { Rain duration } \\
(\mathrm{h}: \mathrm{mn})\end{array}$ & $\begin{array}{c}\text { Previous dry } \\
\text { period (day) }\end{array}$ \\
\hline $\mathrm{d}_{10}$ & 1.2 & 1.0 & 2.3 & $0: 30$ & 0.26 \\
Median & 4.5 & 1.8 & 8.8 & $1: 40$ & 1.41 \\
$\mathrm{~d}_{90}$ & 11.7 & 6.4 & 61.6 & $9: 10$ & 5.63 \\
\hline
\end{tabular}

On the "Ecully" site, flow (measured by a Nivus OCMPro), turbidity (Lange brand, Nephelometry at 860nm, calibration using formazin and a range $=0-4000 \mathrm{FNU}$ ), and conductivity (Yokogawa brand) data were measured between 2004 and 2008 every two minutes. During this period, Metadier and Bertrand-Krajewski (2012) validated these data for 239 rainfall events and 180 dry weather days. This second data set is used for comparison with the results of both Paris sites.

In the following section, turbidity values are transformed into TSS concentrations by applying an average calibration curve as described by (Hannouche et al., 2011; Metadier \& BertrandKrajewski, 2012).

\section{RESULTS AND DISCUSSION}

\section{Volumes, masses and concentrations at the level of rainfall events and dry days}

\section{Distributions}

Sewage flow volume $(V)$, TSS mass $(M)$ and discharge-weighted mean concentration of TSS (C) for both the rainfall events and the dry weather days are illustrated for all the studied catchments in Figure 1 by using "Tukey box plots". This graphical method allows the study of the distribution of a data set using its mean (cross mark), median $\left(Q_{2}\right)$, lower $\left(Q_{1}\right)$ and upper $\left(Q_{3}\right)$ quartiles, and the extremes. Both the lower and upper whiskers define the so-called "adjacent" values, which are determined from the inter-quartile deviation $I Q_{r}=Q_{3}-Q_{1}$, and are greater or equal to $Q_{1}-1.5 * I Q_{r}$ and less or equal to $Q_{3}+1.5 * I Q_{r}$. Volumes and masses for each 
site are expressed in terms of active surface (active hectare = "act.ha"). Note that the unit used with respect to time is "per days" for dry weather and "per event" for wet-weather.

During wet periods on the Paris sites ("Quais", "Clichy" and "Outside Quais"), the distributions of volume, mass and concentration are similar for "Quais" and "Outside Quais", and, consequently, for "Clichy" (no significant differences between the sites are detected by the Friedman paired non-parametric test carried out at a 5\% threshold). The mean specific values are around $140 \mathrm{~m}^{3} /$ act.ha for event volumes (Figure 1, a), $36 \mathrm{~kg} / \mathrm{act}$.ha for event masses (Figure 1, b) and $270 \mathrm{mg} / \mathrm{l}$ for event mean concentration (EMC) (Figure 1, c). The whiskers reveal some sharp variations in volumes, masses and EMC from one rainfall event to another. Indeed, the variations of the considered parameters, expressed as coefficient of variation $(C v)$, are greater than $60 \%$. This variability during wet weather conditions is mainly due to the presence of extreme values especially for volumes and masses.

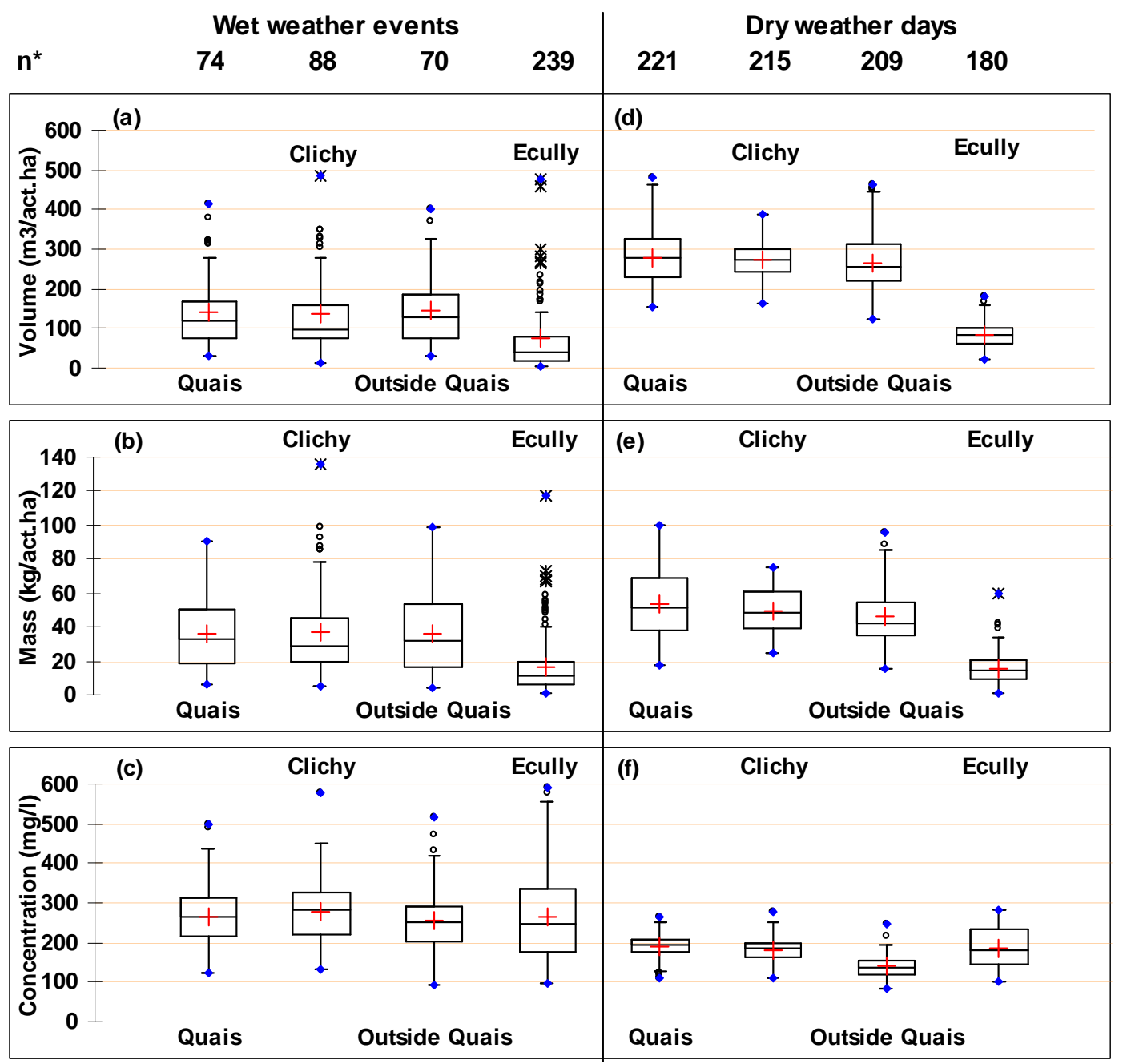

Figure 1: Volume, mass and event mean concentration at the outlet of all the sites for rainfall events (a, b and c) and dry weather days (d, e and $\mathrm{f}) .{ }^{*} n$ is the number of data.

We obtained similar distributions between Paris sites for volumes (Figure 1, d, Paris sites), masses (Figure 1, e, Paris sites) and concentrations (Figure 1, $f$, Paris sites) during dry weather conditions, but their variations are lower than those observed during wet weather conditions ( $C v$ of all parameters during dry weather are less than 50\%). The medians of TSS concentration during dry weather are lower than those observed during wet weather (Figure 1, $f$ ), whereas the specific median of daily production (mass and volume) during dry weather days is 2 times higher than that of rainfall events (Figure 1, e and f, Paris sites). Yet the 24-hr 
dry day production can hardly be compared with the rain event productions concentrating over periods ranging from half hour to 9 hours (first and last deciles of event duration distribution, see Table 2).

These results confirm those of Kafi et al. (2008) obtained from a small data set of rainfall events (between 6 and 16 rainfall events per site including less than 5 common rainfall events between sites) recorded on six embedded catchments in Paris (OPUR sites including our sites: "Quais" and "Clichy") with similar land uses (Table 3). In fact, they observed "no spatial variability" of the on wet weather pollutant masses (except for "Quais" site) and concentrations between the upstream and downstream of a large catchment (surface areas varies between 42 ha and $2581 \mathrm{ha}$ ). The authors of this study attributed the difference in mass at "Quais" site compared to those of other sites to an overestimation of its active surface area. However, we did not observe such difference for 70 rainfall events. This difference may be due to the small number of rainfall events used in their study (Hannouche, 2012).

The similar mean values (or median values) for both mass and volume productions observed for Paris sites, on large data set of rainfall events, suggest that the source density of the two independent parts of the Clichy catchment is homogeneous, as might be expected from similar land uses (dense urban in our case). It would be interesting to find out the minimum spatial scale, for which this coherence is observed and to search for the physical factors able to explain it.

Table 3: Comparison between our results and those obtained by (Kafi et al., 2008) for masses and concentrations $\left(\mathrm{d}_{10}-\mathrm{d}_{90}\right.$ (median)).

\begin{tabular}{c|c|c|c|c|c|c}
\cline { 2 - 7 } & \multicolumn{3}{|c|}{ Our study } & \multicolumn{3}{c|}{ Study of (Kafi et al., 2008) } \\
\hline Sites & Quais & Clichy & $\begin{array}{c}\text { Outside } \\
\text { Quais }\end{array}$ & Quais & Clichy & $\begin{array}{c}\text { OPUR database } \\
\text { (6 sites: 42 to 2581 ha) }\end{array}$ \\
\hline mass & $12-69$ & $10-76$ & $11-67$ & $11-31$ & $24-60$ & $11-61$ \\
(kg/act.ha) & $(33)$ & $(29)$ & $(32)$ & $(15)$ & $(35)$ & $(27)$ \\
$\begin{array}{c}\text { Concentration } \\
(\mathrm{mg} / \mathrm{l})\end{array}$ & $\begin{array}{c}170-339 \\
(267)\end{array}$ & $\begin{array}{c}177-392 \\
(281)\end{array}$ & $\begin{array}{c}173-326 \\
(254)\end{array}$ & $\begin{array}{c}162-339 \\
(233)\end{array}$ & $\begin{array}{c}174-317 \\
(250)\end{array}$ & $\begin{array}{c}174-403 \\
(279)\end{array}$
\end{tabular}

In contrast with Paris sites, whatever the period (dry or wet), the productions (median values of volume and mass) of the "Ecully" residential catchment are twice lower than those observed on the Paris catchments. This can be accounted for by the difference in urbanization (production of wastewater volume per inhabitant (see Table 1), local practices in Paris (street cleaning), etc.). This has a small impact on concentrations: the mean and median concentrations at "Ecully" are similar to those found in Paris (Figure 1, f), with no significant difference at a threshold of 5\% (Mann-Whitney Test). Furthermore, TSS concentrations, regarding combined sewers, in both dry and wet weather conditions, are in good agreement with the values found in the OPUR database (Gasperi et al., 2008; Kafi et al., 2008) or in the literature (Lee and Bang, 2000; Suarez and Puertas, 2005).

\section{Correlations between sites for different rain events}

The specific volume and mass and the EMC obtained for a common rainfall event selected among the 70 events available on both "Quais" and "Clichy" catchments are displayed in Figure $2(a, b, c)$. The correlation of mass, volume, and EMC between both sites is good with a determination coefficient above 0.8 . 

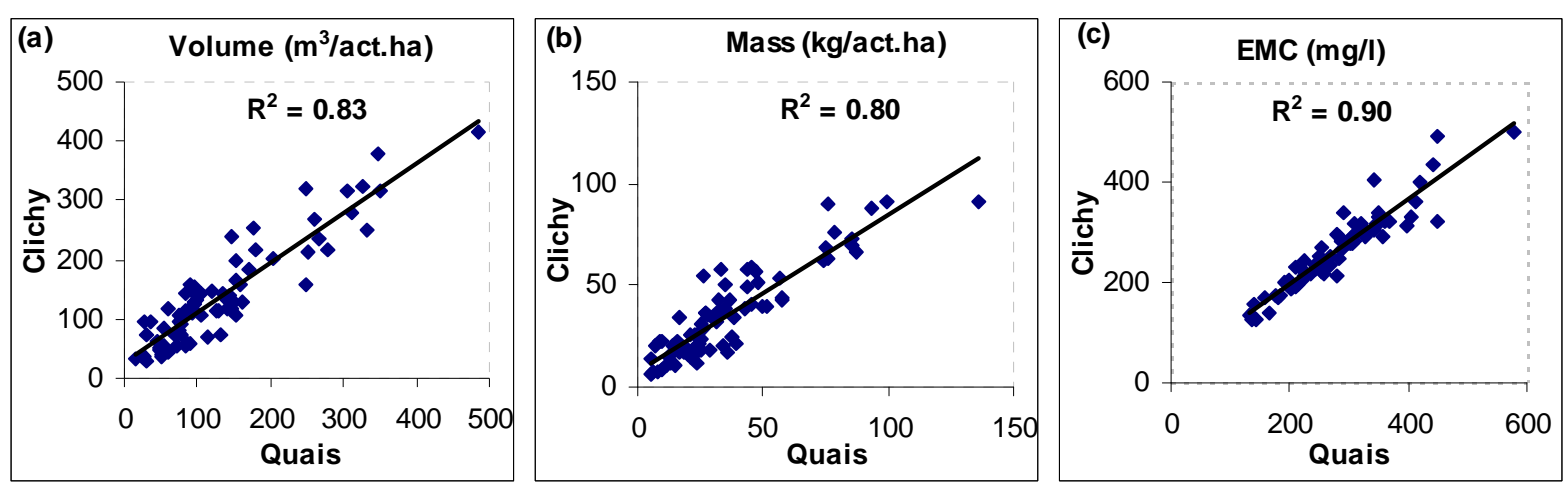

Figure 2: Inter-site comparison of volume (a), mass (b) and event mean concentration (c) for events common to both sites.

The runoff production on densely urbanized areas being closely correlated with rainfall, a high coefficient of correlation between the volumes is expected. This correlation implies a correlation between the event masses. Indeed, on these sites, the event volumes explain about $85 \%$ of the mass variation from one event to another (Hannouche, 2012). The correlation between event masses and volumes is also observed on "Ecully" (Sun and BertrandKrajewski, 2012) and on many other sites. Conversely, the high correlation coefficient between the concentrations is remarkable. We are currently verifying that this correlation between concentrations does not follow from the correlations between both volumes and masses for the dispersion values displayed in Figure 2-c. Until now many attempts to find some significant correlations between concentrations and hydrologic or hydraulic parameters used for describing rain events have failed (Sun and Bertrand-Krajewski, 2012). Yet, in the present case, we think that the correlation between the concentrations in both sites is a clue for some deterministic processes, which control concentrations specifically (i.e., with direct relationship with masses or volumes). Further investigations are needed to validate this assertion.
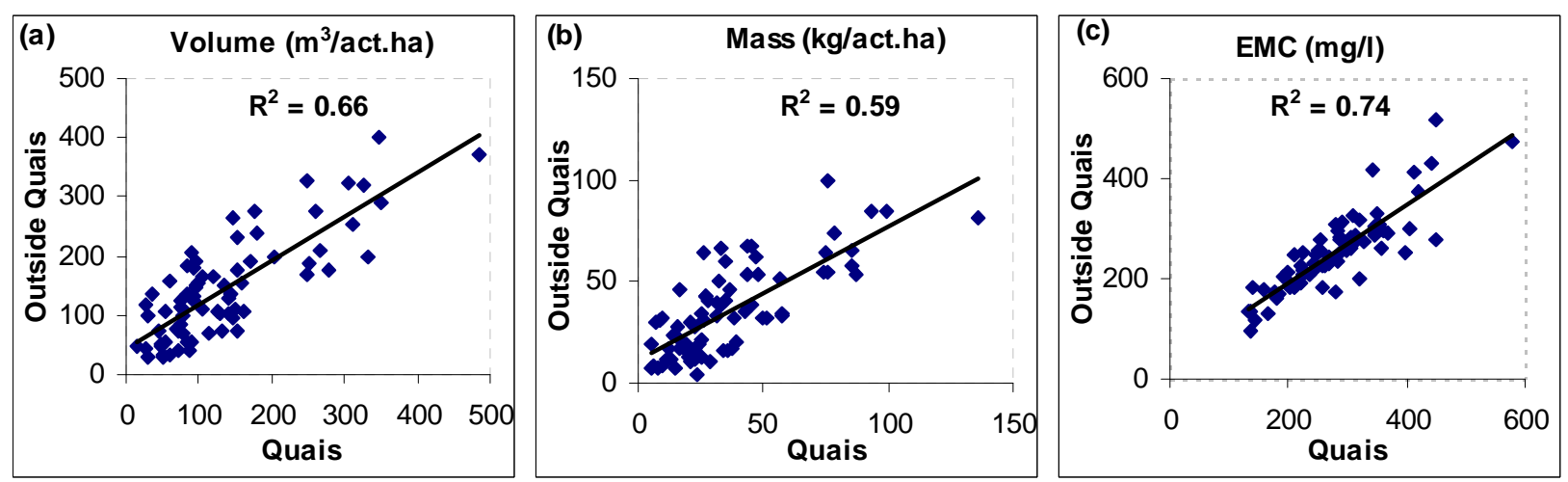

Figure 3: Comparison of volume (a), mass (b) and event mean concentration (c) for events common to "Quais" and "outside Quais" catchments.

The correlations of volumes, masses and EMC of "Quais" and "Outside Quais" catchments are also significant (Figure 3), although the correlation coefficients are lower than those between "Quais" and "Clichy" catchments. These results confirm those discussed above and prove that the correlations between the "Quais" and "Clichy" catchments are not caused by the redundancy between the embedded catchments. Once again, the correlation between the concentrations is strikingly high $\left(R^{2}=0.74\right.$, Figure 3-c).

As a conclusion, we can say that the different values observed from one rainfall event to another may be induced by some processes, which re-occur on different catchments and appear to control either mass production or concentration. 


\section{Contribution of different sources to volume and mass results for each rain event}

\section{Distributions}

The mass discharged at the outlet of a combined sewer system during a rain event $\left(M_{\text {Outlet }}\right)$ has three distinct origins: the wastewater mass discharged during the event $\left(M_{W W}\right)$, the surface runoff mass $\left(M_{S R}\right)$ and the mass of deposits $\left(M_{S D}\right)$ released from the sewer system.

In order to assess the respective contributions, the mass balance between the inlet and the outlet of the sewer network of each catchment area is carried out for each rain event $\left(M_{S D}=M_{\text {Outlet }}-M_{W W}-M_{S R}\right)$. A detailed description of the calculation method is available in (Hannouche et al. in press). The absolute and relative contributions of each source to the water and suspended solids fluxes are presented in Table 4.

These contributions vary greatly from one rain event to another. However, high contributions of deposits are observed for all the three sites: sewer deposit contribution is more than $50 \%$ of the TSS event load on average, and more than $22 \%$ for $90 \%$ of rainfall events. Whereas, wastewater generates a significant fraction of the rainfall events' total volume (40\% to $61 \%$ on average and $\mathrm{d}_{10}$ more than $16 \%$ ) and total load (30\% to $42 \%$ on average and $\mathrm{d}_{10}$ more than $7 \%$ ) on all the three sites. By contrast, surface runoff is characterized by a small contribution to the TSS load ( $8 \%$ to $20 \%$ on average and $d_{90}$ less than $37 \%$ ) with a high contribution to the rainfall events' total volume (more than $39 \%$ on average). For the range $\left(d_{10^{-}} d_{90}\right)$, we can see comparable absolute and relative values between "Quais" and "Clichy" sites which are slightly different from "Ecully"'s relative contributions.

Except for surface runoff, "Ecully"'s absolute contributions are lower than "Quais"'s and "Clichy"'s. The lower population density at "Ecully" site (see Table 1) may be one of the reasons for the lower values of wastewater and deposit absolute contributions than those obtained in Paris combined sewer system. Thus, wastewater smaller absolute contribution seems to induce smaller absolute contribution of deposits accumulated in combined sewers during dry weather periods. As regards runoff contributions, the production is controlled by the runoff concentration distribution, which has been selected for the assessment of this source (Hannouche et al., in press). Here, the different concentration distributions considered as inputs for the mass balance described above, lead to the same mean production.

Table 4: Absolute contributions (in $\mathrm{m}^{3} / \mathrm{act}$.ha and $\mathrm{kg} / \mathrm{act}$.ha) and relative contributions (in \% of each source to event volume and load transit at the outlet of each catchment).

\begin{tabular}{|c|c|c|c|c|c|}
\hline & Source & Catchment & Mean & $\mathrm{d}_{10}$ & $\mathrm{~d}_{90}$ \\
\hline \multirow{6}{*}{$\begin{array}{l}\text { Wet weather } \\
\text { volume }\end{array}$} & \multirow{3}{*}{$\begin{array}{c}\text { WW } \\
\mathrm{m}^{3} / \text { act.ha }(\%)\end{array}$} & Quais & $66(55)$ & $32(37)$ & $122(73)$ \\
\hline & & Clichy & $78(61)$ & $29(42)$ & $137(79)$ \\
\hline & & Ecully & $22(40)$ & $5(16)$ & $50(72)$ \\
\hline & \multirow{3}{*}{$\begin{array}{c}\mathrm{SR} \\
\mathrm{m}^{3} / \text { act.ha }(\%)\end{array}$} & Quais & $61(45)$ & $16(27)$ & $163(63)$ \\
\hline & & Clichy & $62(39)$ & $10(21)$ & $160(58)$ \\
\hline & & Ecully & $56(60)$ & $3(28)$ & $123(84)$ \\
\hline \multirow{9}{*}{$\begin{array}{c}\text { Wet weather } \\
\text { load }\end{array}$} & \multirow{3}{*}{$\begin{array}{c}\text { WW } \\
\text { kg/act.ha }(\%)\end{array}$} & Quais & $13(37)$ & $4(21)$ & $19(47)$ \\
\hline & & Clichy & $12(42)$ & $4(26)$ & $20(65)$ \\
\hline & & Ecully & $5(30)$ & $2(7)$ & $14(57)$ \\
\hline & \multirow{3}{*}{$\begin{array}{c}\text { SR } \\
\text { kg/act.ha }(\boldsymbol{\%})\end{array}$} & Quais & $4(11)$ & $1(5)$ & $9(22)$ \\
\hline & & Clichy & $4(8)$ & $1(4)$ & $8(15)$ \\
\hline & & Ecully & $4(20)$ & $1(6)$ & $10(37)$ \\
\hline & \multirow{3}{*}{$\begin{array}{c}\text { SD } \\
\text { kg/act.ha }(\%)\end{array}$} & Quais & $19(52)$ & $5(37)$ & $41(67)$ \\
\hline & & Clichy & $18(50)$ & $4(27)$ & $40(64)$ \\
\hline & & Ecully & $9(50)$ & $4(22)$ & $19(79)$ \\
\hline
\end{tabular}


For the Paris sites, these results agree with those obtained during the OPUR program (Phase 2) on the same sites (Gasperi et al., 2010) (varies from 47\% to 69\%) and for two events (57\% and 67\%) obtained at Eindhoven-Netherlands by Schilperoort (2011). Moreover, the results show that the relative contribution of sewer deposits is substantial in a sewer system like the "Ecully" catchment. This site, indeed, with a slope of $2.7 \%$, is considered as free of coarse sewer deposits contrary to "Clichy"'s sewer network, whose site, with a slope of $0.14 \%$, is heavily fouled.

\section{Correlation between sites}

Figure 4 presents the comparison between the absolute contributions (in $\mathrm{kg} /$ active $\mathrm{ha}$ ) of wastewater $(W W)$, runoff $(S R)$ and deposits $(S D)$ to the TSS event loads of the "Quais" and "Clichy" sites for the same event.

The correlations are good for the contributions of the three sources between both sites, however somewhat lower than the correlations obtained for the total mass at the outlet (Figure 2-b).
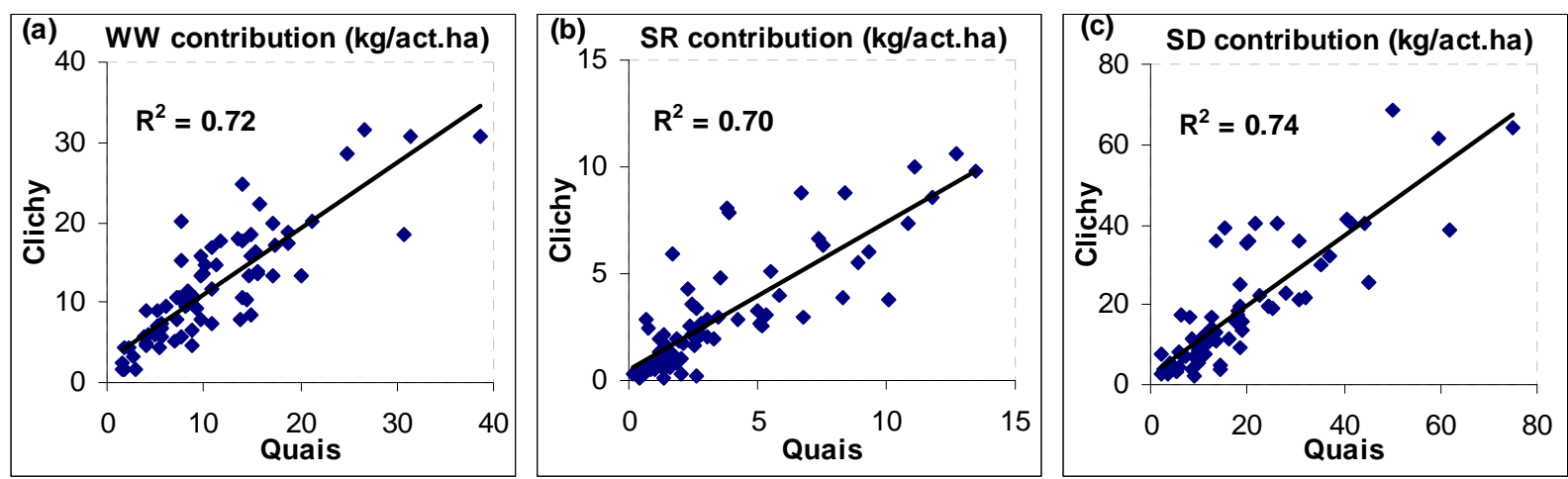

Figure 4: Inter-site comparison of the different contributions to event load transit at the outlet of the catchments for the same rainfall events.

We didn't compare here "Quais" and "Outside Quais" contributions because the many steps of the difference analysis (between sources and between catchment) generate excessive uncertainties (Hannouche et al., in press).

Again, we can conclude that some of the processes for mass production or concentration control are reproducible between catchments with similar land uses. These processes may be related to the mobilization of a variable part of the deposits, accumulated in dry periods, during rain events.

\section{CONCLUSION}

The large database presented in this study is a significant addition to the already available literature. In this paper, it is used to highlight some substantial variations in wet weather TSS fluxes from one rain event to another.

The results obtained for the spatial variations of TSS fluxes and concentrations and the values of the dry weather wastewater and deposit contributions satisfactorily agree with those obtained for other Paris sites with similar land uses.

Moreover, some additional results are used to highlight the following interesting findings:

- Masses and concentrations for different rain events are correlated between sites with similar land uses. The correlation between masses is a consequence of both the correlation between volumes (which is positive for densely urbanized catchments) and 
of the correlations between masses and volumes observed on many sites. The correlation between the concentrations is unexpected and may be a clue for some deterministic processes. However, more investigations need to be carried out to understand the phenomenon better;

- Regarding urban water discharges, wastewater seems that is a decisive factor for two reasons: First, wet weather wastewater generates straightforwardly a significant part of the total event load. Second, the deposits contribution, which is linked to dry weather wastewater deposited in combined sewers during dry weather periods, is also comparatively, though indirectly, substantial;

- The substantial contribution of sewer deposits is not specific to sewer systems like the Paris sewer network but concerns also other systems like, for instance, "Ecully", a site with a steep slope and considered free of coarse sewer deposits.

The great diversity of behaviours is difficult to reproduce using classical global conceptual models. Instead, the some more mechanistic and spatial distribution modelling approach is an innovative way that should be pursued. A method to investigate further the observed spatial coherence could consist of the detailed morphological analysis of the sewer collectors based on criteria related to the production and the transfer of particles in the sewer network.

\section{ACKNOWLEDGMENTS}

The authors gratefully acknowledge the partners of OPUR, OTHU and ONEVU field observatories and SEPIA Conseils firm for their combined financial and technical support.

\section{REFERENCES}

Ashley, R.M., Hvitved-Jacobsen, T., and Bertrand-Krajewski, J.L. (1999). Quo vadis sewer process modelling? Water Science and Technology 39(3), 9-22.

Gasperi, J., Kafi-Benyahia, M., Lorgeoux, C., Moilleron, R., Gromaire, M.C., Chebbo, G. 2008. Wastewater quality and pollutant loads in combined sewers during dry weather periods. Urban Water Journal, 5(4), 305-314.

Gasperi, J., Gromaire, M.C., Kafi, M., Moilleron, R., and Chebbo, G. (2010). Contributions of wastewater, runoff and sewer deposit erosion to wet weather pollutant loads in combined sewer systems. Water Research 44(20), 5875-5886.

Gasperi, J., Zgheib, S., Cladiere, M., Rocher, V., Moilleron, R., and Chebbo, G. (2012). Priority pollutants in urban stormwater: Part 2-Case of combined sewers. Water Research 46(20),6693-6703.

Gromaire-Mertz, M.C., Garnaud, S., Gonzalez, A., and Chebbo, G. (1999). Characterisation of urban runoff pollution in Paris. Water Science and Technology 39(2), 1-8.

Hannouche, A., Chebbo, G., Ruban, G., Tassin, B., Lemaire, B.J., and Joannis, C. (2011). Relationship between turbidity and total suspended solids concentration within a combined sewer system. Water Science and Technology 64(12), 2445-2452.

Hannouche, A. (2012). Analyse du transport solide en réseau d'assainissement unitaire par temps de pluie : exploitation de données acquises par les observatoires français en hydrologie urbaine (Analysis of solid transport in combined sewer network during wet weather: exploitation of data acquired by the French observatories in urban hydrology), $\mathrm{PhD}$ Thesis (in French), Paris-Est University, France, November 2012, 485 p.

Hannouche, A., Chebbo, G., Joannis, C., "in press", published online 5 December 2013. Assessment of the contribution of sewer deposits to suspended solids loads in combined sewer systems during rain events. Environmental Science and Pollution Research, (DOI 10.1007/s11356-013-2395-1). 
Kafi, M., Gasperi, J., Moilleron, R., Gromaire, M.C., Chebbo, G. 2008. Spatial variability of the characteristics of combined wet weather pollutant loads in Paris. Water Research, 42(3), 539-549.

Lacour, C., Joannis, C., and Chebbo, G. (2009). Assessment of annual pollutant loads in combined sewers from continuous turbidity measurements: Sensitivity to calibration data. Water Research 43(8), 2179-2190.

Lee, J.H., and Bang, K.W. (2000). Characterization of urban stormwater runoff. Water Research 34(6), 1773-1780.

Metadier, M., and Bertrand-Krajewski, J.L. (2012). The use of long-term on-line turbidity measurements for the calculation of urban stormwater pollutant concentrations, loads, pollutographs and intra-event fluxes. Water Research 46(20), 6836-6856.

Schilperoort, R.P.S., 2011. Monitoring as a tool for the assessment of wastewater quality dynamics. PhD thesis, TU Delft, The Netherlands, June 2011, 320 p.

Suarez, J., and Puertas, J. (2005). Determination of COD, BOD, and suspended solids loads during combined sewer overflow (CSO) events in some combined catchments in Spain. Ecological Engineering 24(3), 201-219.

Sun, S., and Bertrand-Krajewski, J.-L. (2012). On calibration data selection: The case of stormwater quality regression models. Environmental Modelling \& Software 35(Jul), 61-73. 